\title{
Protection of the environment from ionising radiation in a regulatory context (PROTECT): Review of current regulatory approaches to both chemicals and radioactive substances
}

\author{
D. Copplestone ${ }^{1}$, P. Andersson ${ }^{2}$, N. Beresford ${ }^{3}$, J. Brown $^{4}$, \\ S. Dysvik ${ }^{4}$, J. Garnier-Laplace ${ }^{5}$, J. Hingston ${ }^{1}$, B. Howard ${ }^{3}$, \\ D. Oughton ${ }^{6}$ and $P$. Whitehouse ${ }^{1}$ \\ ${ }^{1}$ Environment Agency, UK \\ ${ }^{2}$ Swedish Radiation Protection Authority, Sweden \\ ${ }^{3}$ Centre for Ecology \& Hydrology, UK \\ ${ }^{4}$ Norwegian Radiation Protection Authority, Norway \\ ${ }^{5}$ Institut de Radioprotection et de Sûreté Nucléaire, France \\ ${ }^{6}$ Norwegian University of Life Sciences, Norway
}

\begin{abstract}
Assessment tools and frameworks have been developed that allow environmental assessments to be conducted and which can be used to demonstrate whether non-human species are protected from the impact of exposure to ionising radiation released under regulation. Frameworks are often tiered, increasing in the level of complexity, input data requirements and need for expert involvement as the assessment moves to successively higher tiers. These are, conceptually, similar to assessment approaches available for chemical risk assessment. What criteria (e.g. numeric benchmarks) should be used, and how these should be defined, are currently under debate, but it is likely that use will be made of approaches developed for setting assessment criteria for chemicals. However it will be necessary to ensure that any assessment criteria developed are fit for use in a regulatory context. This paper reviews the similarities and differences between regulation of, and assessment methods for, chemicals and radioactive substances and presents recommendations regarding how components of chemicals risk assessment may be adopted for radioactive substances.
\end{abstract}

\section{INTRODUCTION}

The need for a system to protect the environment from ionising radiation is now recognised [1] and there has been a considerable international and national effort on this issue over the last decade. The focus has been on collating relevant information and developing approaches to enable regulatory assessments to demonstrate whether the environment is adequately protected from exposure to ionising radiation released under authorisation. Whilst many believe that the ICRP statement [2] ('the Commission believes that the standards of environmental control needed to protect man to the degree currently thought desirable will ensure that other species are not put at risk') continues to be valid, the key is to be able to demonstrate that the environment is protected (as this is difficult using the original ICRP statement). Given developments in conservation legislation, there is now a need to be able to demonstrate environmental protection from ionising radiation in some countries (e.g. as the EC Habitats Directive has been interpreted and implemented in England \& Wales [3]).

Concerns have been expressed both from the nuclear industry and scientific community that the developing approaches may lead to costly regulation. However, there has been a considerable amount of work funded by non-industrial sources to develop tools and approaches that can be used for the purpose of environmental assessment. Some of these tools are freely available and can be used to provide assessments to regulatory bodies. The potential requirement for, and consequences of, regulation should be weighed against the advantages of using nuclear power generation. 
Validation and comparison of the radioecological and dosimetry components of various approaches are required and this has begun through the Biota Working Group of the IAEA's EMRAS programme [4]. It is also important that approaches used are practicable, credible to stakeholders and fit for purpose [5].

The EU EURATOM funded PROTECT project (www.ceh.ac.uk/PROTECT/) has evaluated different approaches to the protection of the environment from ionising radiation and has compared these with the approaches used for chemical contaminants. The projects objective was to provide a scientific justification on which to propose numerical targets for protection of the environment from ionising radiation which could be used in a regulatory context to aid in demonstrating that the environment is adequately protected. To achieve this aim, PROTECT has consulted with industry and regulators widely within Europe, and the broader international community. This paper reports on the critical review that has been conducted to compare approaches to environmental risk assessment for chemical and radioactive substances. The paper also explores how numeric values may work in a regulatory context; methods to derive numeric values of predicted no effect dose rates are reported in [6].

\section{METHODS}

National and international regulatory methodologies and criteria currently applied to environmental protection from radioactive substances have been reviewed. This included assessing the regulatory instruments, procedures and underlying principles, and criteria currently applied in different countries. Environmental regulators, nuclear and non-nuclear industries, international organisations and NGO's were asked to identify the key regulatory instruments and give their views on how environmental regulation is applied.

The gathering of this information was completed through website searches, questionnaires and a workshop which included the participation of experts from outside the PROTECT consortium. Out of approximately 130 organisations contacted, questionnaire responses were received from 50. Regulators and industry each constituted $36 \%$ of the respondents, NGOs and international organisations $10 \%$, and advisory bodies $18 \%$. Although the questionnaires were primarily targeted at regulators and representatives from industry within EU member states, it was recognised that a worldwide perspective would also be valuable and responses were also sought and obtained from, for example, Canada and Australia. Full details are available elsewhere [7].

\section{RESULTS AND DISCUSSION}

The review assessed similarities and differences in approaches for chemical and radioactive substances. It evaluated the extent to which existing approaches fulfil the objectives of environmental protection by looking at what endpoints are being applied, what is acceptable in terms of risk, what levels of compliance are required for chemical and radioactive substances (and are there any differences) and whether there are common themes in the application.

Historically, there has been a different philosophy for regulation of radioactive substances and chemicals. Regulation of radioactive substances has been focused on the protection of humans with the environment as a secondary consideration, whereas for the regulation of chemicals the environment has been the focus. Radiological environmental protection can learn from the evolution of chemical practices which should also negate any confusion that may exist between chemical and radiological environmental protection.

\subsection{Legislation}

Radioactive substance regulation, with respect to environmental protection, is not currently defined by international or European legislation although there are recent recommendations from ICRP on this 
subject [1]. In contrast, regulation of chemicals is usually through the application of internationally accepted standards. A similar approach for radioactive substances could be seen as beneficial as it should facilitate the centralisation of knowledge and effective planning. Harmonisation between approaches for chemical and radioactive substances was considered desirable by respondents; particularly as a similar level of protection for using common assessment endpoints would have a number of advantages. For example, a series of common measurement endpoints, which could be normalised to risk, would allow comparison of the relevant impact from different contaminants. There are practical reasons for differences in terms of how criteria to demonstrate protection for chemicals or radioactive substances are set. For example, criteria for radioactive substances are summed, to include all radionuclides and exposure pathways, whereas in most cases, criteria for chemicals are based on single contaminants and exposure pathways.

\subsection{Protection goal}

Environmental protection goals are often stated in a country's legislation and may be derived from international sources but these are often broad ranging and aspirational in nature using general terms such as: to protect 'the environment', 'ecosystems' or to maintain 'favourable conservation status', 'biological diversity', 'structure and function of habitat/ecosystem', 'protected species' or 'rare species'. This was the case for chemicals and radioactive substances (where the legislation has been interpreted as applying to radioactivity). It was generally felt the overarching protection goal for the regulation of radioactive substances and chemicals should be as consistent as possible.

Following discussions at the workshop, it was decided that PROTECT should focus on protection at the population level with protection goals translated into measurable targets with advice provided on what the tolerable risks associated with these endpoints should be. Endpoints that relate stressor levels to measurement endpoints such as morbidity and reproduction should be targeted because ecological theory shows that these traits determine population sustainability [8]. A caveat is that individuals of rare or endangered species may need to be considered specifically.

\subsection{Similarities and differences between approaches to chemical and radioactive substances risk assessment}

It is clear that the same basic risk assessment paradigm applies to both radiological and chemical assessment. Essentially, it involves comparing an estimate of exposure to some tolerable level usually defined by a concentration or dose rate. If the actual or expected exposure is greater than the tolerable level, then this might trigger some form of action, or at least prompt more accurate exposure estimates. A key element within these risk assessment schemes is the need for thresholds that define acceptable levels of stressors which is considered further elsewhere [6].

The basic generic framework for both radioactive substances and chemicals is: Problem Formulation, Exposure Assessment, Effects Assessment, Risk Characterisation and Risk Management. These steps are included in the more developed radiological assessment tools (e.g. [9]). However, this was intentional as practices in chemical assessment were considered in the development of radiological approaches. Unlike in chemicals risk assessment, there are currently no internationally agreed numeric criteria to determine the interface between an acceptable stressor level and an unacceptable level (i.e. the tolerable level). Nor is there agreement on the methods used to derive such criteria, for radioactive substances in the environment. There is also a need to consider how numeric criteria might be employed within a regulatory context (section 4 ).

A number of respondents considered that they were protecting the environment through demonstrating the protection of humans and consequently most cited $1 \mathrm{mSv} \mathrm{a}^{-1}$ as the numeric limit. A small number of regulators quoted numeric criteria which were being used explicitly to demonstrate the protection of wildlife (Table 1). 
Different approaches have been proposed for deriving numeric criteria for use in risk assessments for radioactive substances, including: (i) purely 'expert judgement'; (ii) determining predicted no effect dose rates using methods agreed for chemicals (e.g. [10]) which may use an assessment factor approach or statistical treatment of data (e.g. a species sensitivity distribution model); and (iii) comparing dose rates to natural background. Whatever method is used, it is important to ensure that the process followed is clearly and transparently documented and that the numbers produced are fit for purpose (e.g. as a screening value). This will require some form of validation against available field data.

Table 1. Numeric values currently being use to demonstrate wildlife is protected from exposure to radioactive substances.

\begin{tabular}{|l|l|}
\hline Regulator & Numeric value \\
\hline Environment Agency, England & $\begin{array}{l}5 \mu \mathrm{Gy} \mathrm{h}^{-1}-\text { screening value to identify sites requiring more detailed assessment. } \\
40 \mu \mathrm{Gy} \mathrm{h}^{-1}-\text { action level as agreed with the statutory consultee for } \\
\text { conservation issues }\end{array}$ \\
\hline DOE, US & $\begin{array}{l}10 \mathrm{mGy} \mathrm{d}^{-1}\left(\sim 400 \mu \mathrm{Gy} \mathrm{h}^{-1}\right)-\text { dose limit for native aquatic animals } \\
40 \mu \mathrm{Gy} \mathrm{h}^{-1} \text { and } 400 \mu \mathrm{Gy} \mathrm{h}^{-1}-\text { benchmarks for terrestrial animals and } \\
\text { plants respectively }\end{array}$ \\
\hline Canada & $\begin{array}{l}20 \mu \mathrm{Gy} \mathrm{h}^{-1}, 220 \mu \mathrm{Gy} \mathrm{h}^{-1}, 110 \mu \mathrm{Gy} \mathrm{h}-1 \\
\text { and freshwater invertebrates and a number of other terrestrial and freshwater } \\
\text { organism groups respectively }\end{array}$ \\
\hline
\end{tabular}

\section{USE OF NUMERIC CRITERIA IN A REGULATORY CONTEXT}

Numeric criteria may be used in a variety of ways as part of a regulatory scheme and this must be considered when deriving them. Two contrasting uses are when a numeric criteria is set as a (i) legally binding condition (a standard) or (ii) trigger in a decision-making framework.

In chemicals, examples of legally binding standards include Air Quality Guidelines and EQSs for the protection of aquatic life under the EC Dangerous Substances Directive. These would typically apply in the ambient environment but are translated into emission limits on discharges to air or water to take account of local factors such as available dilution and dispersion. In this type of direct regulation, compliance must be demonstrated, usually by sampling of the environment or of the undiluted discharge. The consequences of failing the standard can be serious, possibly resulting in legal action and/or an obligation to take steps to reduce emissions to a level where they will comply. It follows that there must be a high degree of confidence that a breach is likely to result in an unacceptable risk.

Numeric values may also be used as trigger (or screening) values where exceedance in itself carries no serious consequences. It merely instigates further work to better understand the risks (either the likely effects of a stressor, or a better understanding of exposure). Such a trigger must sit within some sort of tiered assessment scheme. Since without this context this type of threshold would be meaningless. Such 'triggers' are widely used for assessing the environmental risks of chemicals prior to marketing. Most values being used in radiological assessments of the environment appear to be used in this manner. It is sensible for the trigger to be rather precautionary to try to ensure a low incidence of false negatives. The associated risk of false positives is reasonable because failure to comply with the trigger only prompts a fairly modest response. Under circumstances where the cost of doing more work is high, or if there are too many false positives to be manageable, it may be prudent to adjust the trigger. Under these circumstances the level of precaution is traded-off against these practical and economic considerations.

\subsection{Use of numeric values in a regulatory context - recommendations}

Taking these points into consideration the 'ideal' (i.e. that which we should aim for) risk assessment scheme that we think should be applied for radioactive substances is shown in Figure 1. Within the ideal scheme, there are two key differences to the approach that would be used in chemicals. 
The first difference is our intention to employ a number of screening levels (for different organism groups) for determining when to continue the assessment. This is because experience of conducting risk assessments has demonstrated that, unlike chemicals, often we are comparing the most exposed wildlife groups (due to the habits and occupancy in the environment) to a screening value determined by the most radiosensitive wildlife group. This clearly can lead to more assessments exceeding a screening value and requiring more detailed assessment. By comparing exposure predictions for wildlife groups to screening levels determined based on similar levels of radiosensitivity, this problem can be addressed and therefore improve the fitness for purpose of the assessment process. There may be a problem however, because of lack of suitable good quality effects data on which to derive the screening values for the different taxonomic groups. There may, therefore need to be an interim system for application.

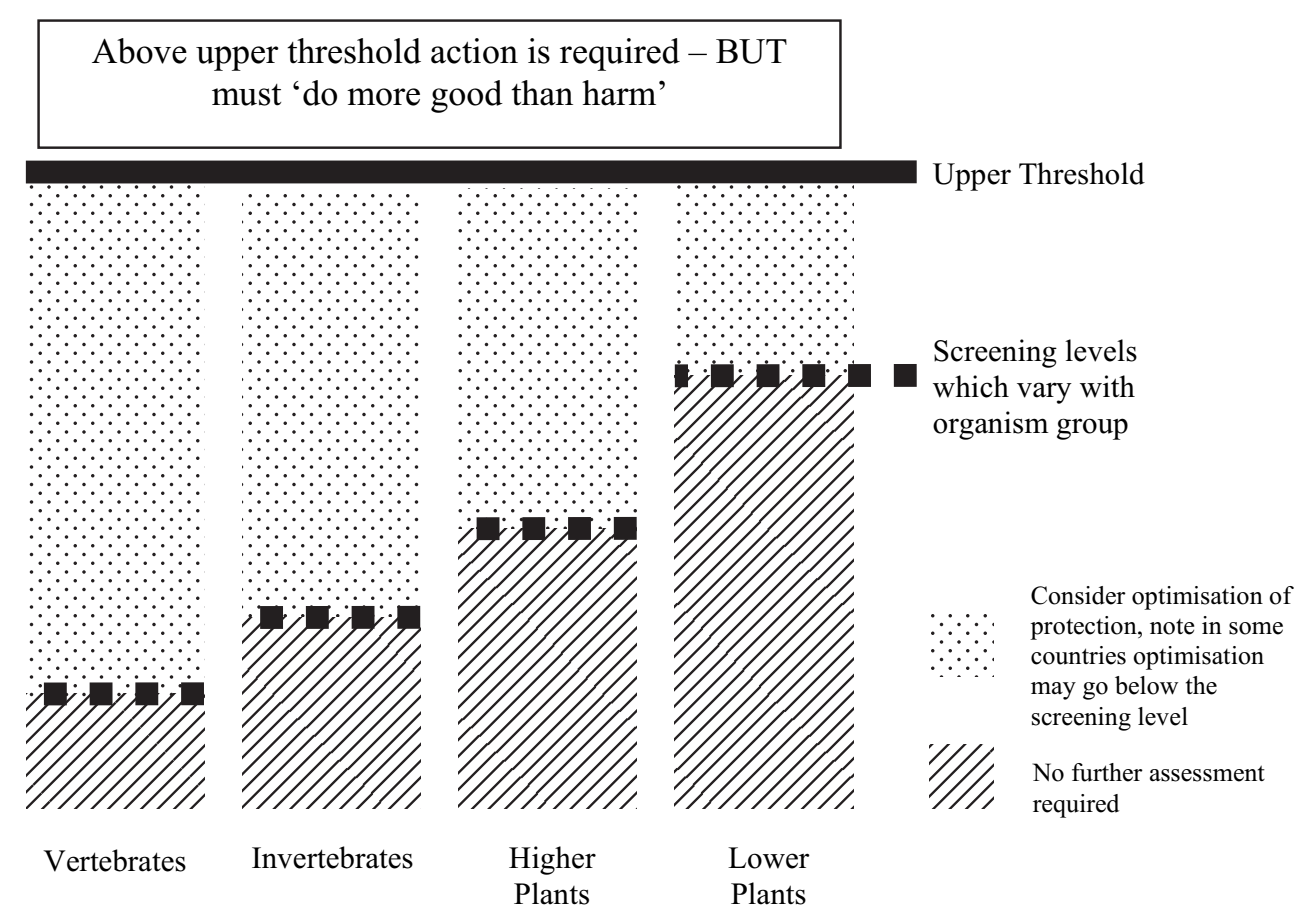

Figure 1. Application of numeric criteria within an 'ideal' risk assessment framework using example wildlife groups - note this is the expected grouping for the screening values but data are still being evaluated.

The second difference is related to application of an upper threshold. This upper threshold has value within radiological risk assessment in the same way as dose constraints or limits can be applied within the human radiological system of protection, although not all countries apply the human system in this way. For environmental protection, the upper threshold could provide additional information about how important environmental criteria might be when considering the need and the drivers for optimisation of protection. For example, the closer the exposure predictions are to the upper value the more weight should be given to environmental criteria compared with human radiological protection. In other words, we anticipate that few, if any, environmental assessments will be conducted without reference to human radiological protection and having an upper threshold could provide assistance to an assessor (an issue identified, and debated, during consultation within PROTECT).

The information in this paper is contributing to other PROTECTs activities to determine the appropriateness of numeric benchmarks suggest for use to demonstrate environmental protection from the effects of ionising radiation and to address the issues of the cost, or burden, of any environmentally 
derived regulation $[5,6]$. The overall outputs from the PROTECT project will contribute to the debate on the environmental consequences of our use of radioactive substances.

\section{Acknowledgments}

The authors would like to thank the participants of the workshop (held in Chester, March 2007) associated with this work (see http://www.ceh.ac.uk/protect/pages/workshops.html). This work was supported by the EC-EURATOM $6^{\text {th }}$ Framework Programme and forms part of the PROTECT project (FI6R-036425); the financial support of the EC is gratefully acknowledged.

\section{References}

[1] ICRP Publication 103 Annals of the ICRP 37 (2007).

[2] ICRP Publication 60. Annals of the ICRP 21 (1991).

[3] Copplestone D., Wood M.D., Bielby S., Jones S.R., Vives J., Beresford N.A. and Zinger I. Radioprotection 40 (2005) S893-S898.

[4] Beresford N.A., Barnett C.L., Beaugelin-Seiller K., Brown J.E., Cheng J-J., Copplestone D., Gaschak S., Hingston J.L., Horyna J., Hosseini A., Howard B.J., Kamboj S., Kryshev A., Nedveckaite T., Olyslaegers G., Sazykina T., Smith J.T., Telleria D., Vives i Batlle J., Yankovich T.L., Heling R., Wood M.D. and Yu C. (this issue).

[5] Beresford N.A., Beaugelin-Seiller K., Brown J.E., Copplestone D., Hosseini A. and Howard B.J. Radioprotection (this issue).

[6] Andersson P., Beaugelin-Seiller K., Beresford N.A., Copplestone D., Della Vedova C., GarnierLaplace J., Howard B.J., Howe P. and Oughton D.H., Numerical benchmarks for protecting biota against radiation in the environment: proposed levels and underlying reasoning, Deliverable 5B (draft) of the EC PROTECT project (Contract Number: 036425 (FI6R)), Available from: http://www.ceh.ac.uk/protect (2008).

[7] Hingston J.L., Andersson P., Beresford N.A., Brown J., Copplestone D., Garnier-Laplace J., Howard B.J. and Whitehouse P. A review of approaches to protection of the environment from chemicals and ionising radiation: Requirements and recommendations for a common framework. Deliverable 3, PROTECT: Protection of the environment from ionising radiation in a regulatory context (contract number 036425 (FI6R)), www.ceh.ac.uk/protect (2007).

[8] Forbes V.E., Calow P. and Sibly R.M. Environ. Toxicol. Chem. 20 (2001) 442-447.

[9] Beresford N., Brown J., Copplestone D., Garnier-Laplace J., Howard B., Larsson C-M., Oughton D., Prohl G. and Zinger I. D-ERICA: An integrated approach to the assessment and management of environmental risks from ionising radiation - Description of purpose, methodology and application. ERICA (Contract Number:FI6R-CT-2004-508847) pp 82 www.ceh.ac.uk/protect (2007).

[10] European Chemicals Bureau Technical Guidance Document in support of Commission Directive 93/67/EEC on Risk Assessment for new notified substances, Commission Regulation (EC) No 1488/94 on Risk Assessment for existing substances and Directive 98/8/EC of the European Parliament and of the Council concerning the placing of biocidal products on the market. Part II. European Commission Joint Research Centre EUR 20418 EN/2 pp 328 (2003). 